\title{
Adsorption of Diclofenac Sodium Using Low-Cost Activated Carbon in a Fixed-Bed Column
}

\author{
Fadirah Fadzail ${ }^{1(\mathbb{D})}$, Masitah Hasan ${ }^{1,2 * \mathbb{C}}$, Naimah Ibrahim ${ }^{1,2} \mathbb{( \mathbb { D }}$, Zulfakar Mokhtar $\left.{ }^{2,3} \mathbb{(}\right)$, Akas Yekti \\ Pulih Asih 4 (D), Achmad Syafiuddin 4(D) \\ 1 Faculty of Civil Engineering Technology, Universiti Malaysia Perlis, Kompleks Pusat Pengajian Jejawi 3, 02600 Arau, \\ Perlis, Malaysia \\ 3 Centre of Excellence (COE), Water Research and Environmental Sustainability Growth (WAREG), Universiti Malaysia \\ Perlis, Kompleks Pusat Pengajian Jejawi 3, 02600 Arau, Perlis, Malaysia \\ 2 Faculty of Chemical Engineering Technology, Universiti Malaysia Perlis, Kompleks Pusat Pengajian Jejawi 3, 02600 \\ Arau, Perlis, Malaysia \\ 4 Department of Public Health, Universitas Nahdlatul Ulama Surabaya, 60237 Surabaya, Indonesia \\ * Correspondence: masitah@unimap.edu.my (M.H.);
}

Scopus Author ID 35753686300

Received: 30.09.2021; Revised: 1.11.2021; Accepted: 5.11.2021; Published: 5.12.2021

\begin{abstract}
In recent years, the presence of pharmaceutical contaminants, such as diclofenac sodium (DCF) in water bodies and their potential influence on aquatic organisms gained much attention. As a result of high demand and usage by consumers, in addition to incomplete removal during wastewater treatment, pharmaceutical contaminants will end up on water surfaces. To mitigate this problem, the elimination of DCF by employing activated carbon derived from Dillenia Indica peels was evaluated. The adsorption of DCF was performed in a continuous process. The findings showed that the adsorption of DCF was favorable at a lower flow rate, greater bed height, and initial DCF concentration, with the highest removal percentage of $44.93 \%$. To assess the characteristics of the breakthrough curve of DCF, the adsorption data were used to match three distinct adsorption models, namely, Boharts and Adam, Yoon-Nelson, and Thomas. The breakthrough results were well-fitted with these models, as the values of $\mathrm{R}^{2}$ for all models and parameters were higher than 0.88 . Thus, it was concluded that the activated carbon from Dillenia Indica can effectively remove DCF from an aqueous solution.
\end{abstract}

Keywords: adsorption; Dillenia Indica; fixed-bed column; activated carbon.

(C) 2021 by the authors. This article is an open-access article distributed under the terms and conditions of the Creative Commons Attribution (CC BY) license (https://creativecommons.org/licenses/by/4.0/).

\section{Introduction}

Diclofenac sodium (DCF) is extensively used by humans to manage pain. DCF is a type of non-steroidal anti-inflammatory drug (NSAID) that reduces swelling and relieves pain for conditions affecting joints and muscles, such as osteoarthritis [1]. This drug is available in various forms, such as tablets, gel, and patches that provide significant anti-inflammatory and analgesic effects, as well as superior safety and tolerability compared with other tricyclic nonsteroidal anti-inflammatory medications [2]. This drug has existed for the last four decades and is known worldwide, with approximately a billion patients consuming this drug until now $[3,4]$. The high demand for DCF has led to large productions of this drug worldwide.

Every house could have at least one type of NSAIDs, whether diclofenac, ketoprofen, or ibuprofen. Large usage of these drugs will lead to an environmental problem when they are not disposed of properly. NSAIDs that have been consumed by the body are not completely metabolized and will be excreted from the body through urine and feces [5]. Subsequently, 
NSAIDs will flow into rivers or sewage systems. An investigation was performed by a previous researcher to trace DCF in the marine environment of the Saudi Arabian Red Sea. This study has successfully detected DCF, with concentrations up to $3000 \mathrm{ng} / \mathrm{L}$ [6]. This medicine has made its way into the environment, as wastewater is not handled properly due to the lack of knowledge and improper wastewater treatment facilities. This condition will not only cause harm to humans, but it can also affect aquatic lifeforms. As for humans, those who live in rural areas will be affected because they usually consume water directly from the nearest source without any purification for their daily use. Several studies found that the presence of drugs in the ecosystem has disrupted the life of fish and other aquatic organisms. A recent study was conducted to determine the long-term exposure of NSAIDs to mussels. The findings showed an accumulation of these drugs in mussels, which altered their internal system, including their immune system and the genetic information within the cells [7].

Thus, several methods have been introduced to control the presence of these drugs in the environment. Researchers have established numerous methods to find the best way to remove these drugs. Some of these methods are by using nanofiltration [8], coagulation in a membrane bioreactor [9], and ozonation [10]. However, some of these methods require expensive equipment and may even contribute by-products that further affect the environment and humans. The adsorption method is currently the simplest to reduce and eliminate emerging contaminants [11]. To implement the adsorption process, an adsorbent is usually used as the substance that will absorb the pollutant. Activated carbon has been significantly explored as an adsorbent in the field of adsorption. Agricultural waste or biomass is often utilized as the precursor in the manufacture of activated carbon. For example, Astragalus Mongholicus, an agro-industrial waste, was used to remove DCF from aqueous solutions [12].

Apart from the batch adsorption technique, fixed-bed column adsorption can also be applied for removing contaminants. In a fixed-bed column adsorption system, the adsorbate is allowed to continuously flow throughout the glass column. Various industries prefer column adsorption because it is efficient in handling large concentration differences [13]. The fixedbed column can also handle large amounts of adsorbate at once. Thus, adsorption experiments at the laboratory scale can be scaled up to fit large-scale industrial needs. In a previous study, the removal of amoxicillin was studied using batch and column adsorption systems with commercial activated carbon [14]. Their study used a fixed-bed column adsorption system at different concentrations, flow rates, and adsorbent dosages. Another study zed biochar to remove diclofenac and cephalexin using both batch and column adsorption systems [15]. The findings showed that the produced activated carbon was successful in treating pharmaceuticals in wastewater plants. Several empirical models are often used in column adsorption, namely, the Thomas, Yoon-Nelson, and Boharts and Adam models. These mathematical models contribute to a different assumption describing different parts of the breakthrough curve [16].

In this study, DCF adsorption using activated carbon as adsorbents was implemented. The activated carbon was produced using a low-cost material known as Dillenia Indica peels. Since other studies have not reported using Dillenia Indica peels as activated carbon, this study implemented a chemical activation technique to produce activated carbon. The resultant activated carbon was then evaluated for its effectiveness in removing DCF contaminants via column adsorption. Then, three adsorption models were executed to estimate the behavior of the DCF uptake and the applicability of variables in developing the continuous adsorption experiment. 


\section{Materials and Methods}

\subsection{Chemicals.}

Dillenia Indica peels were utilized as the raw material in this study to produce activated carbon. Analytical grade reagents were employed in every experiment. Phosphoric acid $\left(\mathrm{H}_{3} \mathrm{PO}_{4}, 85 \%\right)$ was obtained from Merck, Germany, while sodium hydroxide $(\mathrm{NaOH})$ and denatured ethanol $\left(\mathrm{C}_{2} \mathrm{H}_{5} \mathrm{OH}, 95 \%\right)$ were obtained from $\mathrm{Hmbg}$. Another chemical, hydrochloric acid (HCl, 37\%), was supplied by Fisher Scientific. The adsorbate, diclofenac sodium (DCF) was purchased from Alfa Aesar, UK.

\subsection{Preparation of activated carbon.}

Dillenia Indica peels were utilized in the chemical activation technique to generate activated carbon. The raw peels were washed using tap water and dried under the sun for several days. The peels were then cut into smaller pieces and sieved to obtain similar-sized samples. The soaking process took place, where the smaller size Dillenia Indica peels were soaked for $24 \mathrm{~h}$ in phosphoric acid $\left(\mathrm{H}_{3} \mathrm{PO}_{4}\right)$, with an impregnation ratio of 2:1 (dry weight of sample: dry weight of chemical). After $24 \mathrm{~h}$, the impregnated Dillenia Indica peels were dried overnight using an oven at $95^{\circ} \mathrm{C}$. Next, the dried sample was placed in a tube furnace for the carbonization process, which took $2 \mathrm{~h}$ at $500{ }^{\circ} \mathrm{C}$ with a $30 \mathrm{~mL} / \mathrm{min}$ flow of nitrogen gas. The sample was washed using acid and base to neutralize the $\mathrm{pH}$ of the sample once the sample had sufficiently cooled down to room temperature. Distilled water was used in the last step of the washing process until $\mathrm{pH} 6$ to $\mathrm{pH} 7$ was obtained. Then, the activated carbon was ready to be used.

\subsection{Preparation of adsorbate.}

The adsorbate was prepared with a simple dilution using distilled water. A concentrated DCF solution of $100 \mathrm{mg} / \mathrm{L}$ was produced by mixing a sufficient quantity of DCF with water in a volumetric flask. This solution was further diluted using distilled water to the required working concentration. The DCF solution was detectable at a wavelength of $276 \mathrm{~nm}$ when analyzed using a UV-Vis spectrophotometer.

\subsection{Column adsorption experiment.}

In this study, fixed-bed column adsorption was a process that occurred in a cylindrical glass column, measuring $2 \mathrm{~cm}$ in diameter, where the adsorbent was placed inside the column. The adsorbate solution was passed through the column in a continuous flow. The bottom of the glass column was fitted with a layer of support grid to ensure that the materials inside the column were secured.

First, glass beads were inserted into the column, followed by a sheet of glass wool. The adsorbent (activated carbon) was then placed inside the column in the required dosage. Finally, the adsorbent layer was covered with another sheet of glass wool and another layer of glass beads to ensure that the adsorbent inside the column could not move. The column was connected to other instruments before running the experiment. A schematic diagram of the fixed-bed column adsorption is shown in Figure 1 below.

This study has focused on three conditions, namely, the effects of adsorbent height, initial concentration of DCF, and flow rate of DCF. The amount of solution that flowed into 
the fixed-bed column at a specific time was controlled using a peristaltic pump. As the solution flowed into the column, the desired sample solution was collected at a regular interval at the outlet. The mass per unit volume of adsorbate was measured using a Shimadzu UV-1800 Spectrophotometer, Japan. This study was conducted in ambient conditions, and all results were utilized in analyzing the breakthrough curve.

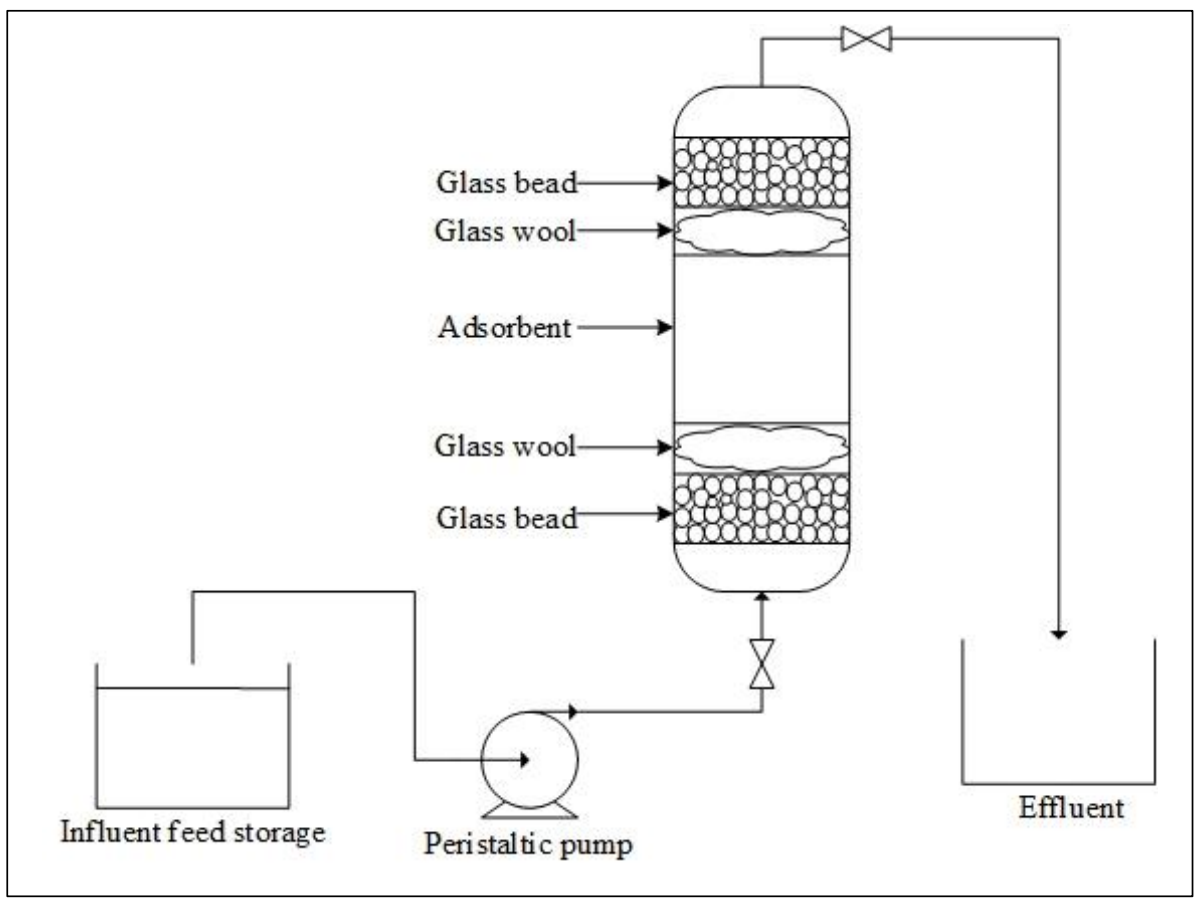

Figure 1. Schematic diagram of a fixed-bed column adsorption system.

\subsection{Adsorption column performance.}

A plot of breakthrough curves at different conditions was obtained by plotting $C_{t} / C_{o}$ versus time to assess the behavior of DCF uptake by the adsorbent in the column. The volume of effluent that flowed through the column was computed by employing the following Equation 1 [17]:

$$
V_{\text {eff }}=Q t_{\text {total }}
$$

where, $t_{\text {total }}$ is the time for the solution to flow inside the column (min) and $Q$ is the volume of the solution at a specific time $(\mathrm{mL} / \mathrm{min})$. Other important parameters for analyzing column adsorption included the total adsorbate adsorbed, $q_{\text {total }}$, and total adsorbate sent to the column, $m_{\text {total }}$. Both parameters were calculated using the following Equation 2 and Equation 3 [18]:

$$
\begin{gathered}
q_{\text {total }}=\frac{Q A}{100} \\
m_{\text {total }}=\frac{Q C_{O} t_{\text {total }}}{1000}
\end{gathered}
$$

where, $\mathrm{z}$ the region below the breakthrough curve is indicated by $A$, while $Q$ refers to the rate of solution flowing into the column ( $\mathrm{mL} / \mathrm{min})$, by performing integration of the plot of adsorbed adsorbate, in terms of concentration $\left(C_{a d}\right)(\mathrm{mg} / \mathrm{L})$ versus time $(t)$, the value of $A$ can prevail. $C_{a d}$ may be calculated by subtracting the effluent concentration at time $t, C_{t}$, against initial concentration, $C_{o}$.

Meanwhile, the removal percentage of DCF can be assessed using Equation 4 below [18]: 


$$
\% R=\frac{q_{\text {total }}}{m_{\text {total }}} \times 100
$$

where, the value of $q_{\text {total }}$ and $m_{\text {total }}$ can be calculated using Equation 2 and Equation 3, respectively.

\subsection{Modelling of column adsorption.}

The breakthrough curves obtained from the experiment were analyzed using three models: Bohart and Adams, Yoon-Nelson, and Thomas. These models were used to assist in the prediction of the column's dynamic behavior. Owing to their ease of formulation and linearization, these three models are often employed in the study of column adsorption.

\subsubsection{Thomas model.}

The column adsorption performance was analyzed using a general Thomas model. It was deduced that the adsorbate flow inside the column was a plug flow with no axial dispersion [19]. This model is thought to be gleaned from Langmuir isotherm and second-order kinetics models, in which adsorption involves mass transfer at the boundary and chemical reactions [20]. Thomas model's linear and nonlinear forms are shown by the following Equation 5 and Equation 6, respectively:

$$
\begin{aligned}
& \ln \left(\frac{C_{0}}{C}-1\right)=\frac{K_{T H} q_{O} M}{Q}-K_{T H} C_{O} t \\
& \frac{C}{C_{O}}=\frac{1}{1+\exp \frac{K_{T H} q_{O} M}{Q}-K_{T H} C_{O} t}
\end{aligned}
$$

where, the rate constant of Thomas model $(\mathrm{mL} / \mathrm{mg} \cdot \mathrm{min})$ is denoted as $K_{T H}$, meanwhile, $M$ is the adsorbent mass $(\mathrm{g})$ of the column, and $q_{o}$ is the amount of adsorbate uptake by the adsorbent per unit mass $(\mathrm{mg} / \mathrm{g}) . C_{o}, t$, and $Q$ are denoted as the initial concentration $(\mathrm{mg} / \mathrm{L})$, time $(\mathrm{min})$, and flow rate $(\mathrm{mL} / \mathrm{min})$, respectively. A straight-line plot may be generated using results from Equation 5 by plotting $\ln \left[\left(C_{o} / C\right)-1\right]$ against time. Based on the plot, the value for $q_{o}$ and $K_{T H}$ can be quantified from the gradient and the intercept. The Thomas model's nonlinear equation yields a breakthrough curve of $C / C_{O}$ versus $t$.

\subsubsection{Yoon-Nelson model.}

According to the breakthrough model of Yoon-Nelson, a reduction in the adsorption proportion of adsorbate corresponds to the adsorption process and the breakthrough [21]. Explanation regarding data on the nature of adsorbent, adsorption of physical variables, and adsorbate properties are not necessary for this model [20,22]. This model is less complicated than other breakthrough models. The expressions of this model are as follows:

$$
\begin{gathered}
\ln \left(\frac{C_{0}}{C}-1\right)=K_{Y N} \tau-K_{Y N} t \\
\frac{C}{C_{o}}=\frac{1}{1+\exp \left(K_{Y N} \tau-K_{Y N} t\right)}
\end{gathered}
$$

where, $K_{Y N}$ and $\tau$ is the Yoon-Nelson rate constant (1/min) and the time (min) when the breakthrough curve reaches $50 \%$. 
2.6.3. Bohart and Adams model.

In the Bohart and Adams model, the uptake rate corresponds to the adsorbate's concentration and the residual capacity of activated carbon [23]. The equation for Bohart and Adams is presented below in linear and nonlinear forms:

$$
\begin{gathered}
\ln \left(\frac{C_{0}}{C}-1\right)=\frac{K_{B A} N_{O} L}{u}-K_{B A} C_{O} t \\
\frac{C}{C_{O}}=\frac{1}{1+\exp \left(\frac{K_{B A} N_{O} L}{u}-K_{B A} C_{O} t\right)}
\end{gathered}
$$

where, $N_{o}$ is the amount of adsorbate uptake per unit volume $(\mathrm{mg} / \mathrm{L})$, and $K_{B A}$ is the mass transfer coefficient $(\mathrm{L} / \mathrm{mg} \cdot \mathrm{min})$. The height of the adsorbent inside the column $(\mathrm{cm})$ is assigned as $L$, and $u$ is the superficial velocity of the adsorbate $(\mathrm{cm} / \mathrm{min})$. The linear equation for the Bohart and Adams model will yield a plot of $\ln \left[\left(C_{o} / C\right)-1\right]$ versus time $(\mathrm{min})$. The intercept and slope of the plot may be used to calculate the values of $K_{B A}$ and $N_{O}$.

\section{Results and Discussion}

\subsection{Effect of bed height.}

The plot of the breakthrough curves for the uptake of DCF at different adsorbent heights is shown in Figure 2. Bed heights of 50, 75, and $100 \mathrm{~mm}$ were used, where the operating parameters were kept constant at $40 \mathrm{mg} / \mathrm{L}$ of DCF concentration and $10 \mathrm{~mL} / \mathrm{min}$ of flow rate. The findings revealed that the increase in bed height from 50 to $100 \mathrm{~mm}$ could cause a decrease in the breakthrough curve. Table 1 shows the parameters for the breakthrough curve at different adsorbent heights.

The breakthrough curves began to decrease when the amount of adsorbent in the bed was increased, which further increased the total time for the adsorption process to complete, from 130 to $150 \mathrm{~min}$. This change happened because more active sites became available for the sorption process to occur [24].

\begin{tabular}{|c|c|c|c|c|c|}
\hline Bed height (mm) & $t_{\text {total }}(\mathrm{min})$ & $V_{e f f}(\mathbf{m L})$ & $q_{\text {total }}(\mathrm{mg})$ & $m_{\text {total }}(\mathrm{mg})$ & \% Removal \\
\hline $\mathbf{5 0}$ & 130 & 1300 & 18.13 & 60.84 & 29.80 \\
\hline 75 & 140 & 1400 & 26.86 & 63.31 & 42.43 \\
\hline 100 & 150 & 1500 & 30.63 & 68.18 & 44.93 \\
\hline$\stackrel{ن}{ \pm}$ & & & & $\begin{array}{l}50 \mathrm{~mm} \\
75 \mathrm{~mm} \\
100 \mathrm{~mm}\end{array}$ & \\
\hline & & & 100 & 150 & \\
\hline
\end{tabular}

Table 1. Parameters for breakthrough curves for the removal of DCF at different bed heights.

Figure 2. Breakthrough curves at different bed heights. 
A longer time was needed for a higher bed to achieve saturation since a higher amount of adsorbent was present [25]. Additionally, the mass transfer zone was increased, which slowed the progress to an equilibrium condition, where no additional mass transfer occurred, compared with when a shorter bed height was used. In terms of removal percentage, an increase in the height of the bed had also led to a higher amount of DCF being removed, thus, promoting a greater removal percentage in the column. These results are in line with those published in a previous investigation [26,27].

\subsection{Effect of flow rate.}

The effect of different adsorbate flow rates on the adsorption process was explored within a range of 10 to $30 \mathrm{~mL} / \mathrm{min}$. The height of the adsorbent and DCF concentration remained unchanged at $75 \mathrm{~mm}$ and $40 \mathrm{mg} / \mathrm{L}$, accordingly. The plot of the breakthrough curves for different volumes of adsorbate flowing into the column is depicted in Figure 3. At the lowest flow rate of $10 \mathrm{~mL} / \mathrm{min}$, the slowest breakthrough curve was obtained, which reflected the time needed to reach equilibrium concentration. The slow flow of adsorbate into the column allowed more time for the adsorbate molecules to diffuse into the adsorbent and thus, to result in a higher amount of DCF adsorbed throughout the column [28]. The saturation time was decreased when the DCF flow rate was increased from 10 to $30 \mathrm{~mL} / \mathrm{min}$. These results matched the results obtained in a study performed by [24].

Table 2. Parameters for breakthrough curves at different flow rates.

\begin{tabular}{c|c|c|c|c|c} 
Flowrate $(\mathbf{m L} / \mathbf{m i n})$ & $\boldsymbol{t}_{\text {total }}(\mathbf{m i n})$ & $\boldsymbol{V}_{\text {eff }}(\mathbf{m L})$ & $\boldsymbol{q}_{\text {total }}(\mathbf{m g})$ & $\boldsymbol{m}_{\text {total }}(\mathbf{m g})$ & \% Removal \\
\hline $\mathbf{1 0}$ & 140 & 1400 & 27.16 & 63.31 & 42.90 \\
\hline $\mathbf{2 0}$ & 130 & 2600 & 16.06 & 117.96 & 13.61 \\
\hline $\mathbf{3 0}$ & 120 & 3600 & 11.52 & 156.21 & 7.37
\end{tabular}

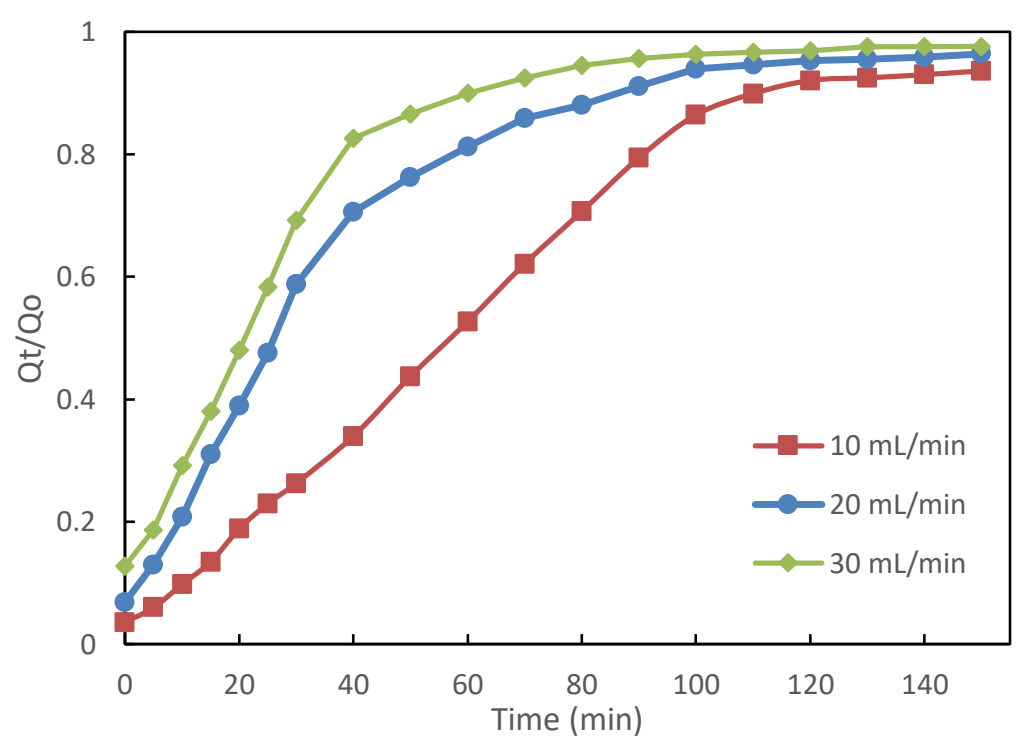

Figure 3. Breakthrough curves at different flow rates.

As shown in Table 2, the total treated volume of DCF is increased with the increasing flow rate. Although a higher concentration of DCF was being treated, the total adsorbate adsorbed by the activated carbon, $q_{\text {total }}$, at 10,20 , and $30 \mathrm{~mL} / \mathrm{min}$ was low at 27.16, 16.06, and $11.52 \mathrm{mg}$, respectively. This was due to the low exposure period between DCF and the adsorbent since the flow of adsorbate through the column was fast. The removal percentage of DCF continued to decrease when the DCF flow rate was increased, owing to the reduced adsorbate residence time in the column and less adsorbent concentration being adsorbed [19]. 
The removal percentage was decreased from $42.90 \%$ to $7.37 \%$, with DCF flow rate of 10 to 30 $\mathrm{mL} / \mathrm{min}$.

\subsection{Effect of initial concentration.}

The effect of initial concentration played a significant role in the column adsorption of DCF. The DCF concentration was changed from 20 to $60 \mathrm{mg} / \mathrm{L}$, with other operating parameters kept constant at a bed height of $75 \mathrm{~mm}$ and flow rate of $10 \mathrm{~mL} / \mathrm{min}$. The curves for different initial DCF concentrations are depicted in Figure 4. Steeper breakthrough curves were found at higher initial concentrations, and the curves started to shift to the right and became slower when the initial concentration was decreased. As shown in Table 3, the volume of adsorbate treated, Veff, is reduced from $1500 \mathrm{~mL}$ to $1200 \mathrm{~mL}$ when the initial DCF concentration increases. A shorter time was required for the breakthrough to achieve equilibrium for the removal of DCF at higher concentrations. When low initial concentrations were passed through the column, the pores on the adsorbent were slowly filled with the adsorbate in the early stage. At higher initial concentration, the pores on the adsorbent were rapidly filled with DCF molecules, as a higher amount of DCF molecules were present. As time went by, the adsorbent pores were filled with adsorbate molecules, and thus, no net adsorption occurred, resulting in low exhaustion time at a higher concentration.

The higher concentration of DCF present and the rapid loading of DCF onto the adsorbent's pores have increased the uptake of DCF molecules at $27.68 \mathrm{mg}$, with $60 \mathrm{mg} / \mathrm{L}$. The total DCF molecules, $m_{\text {total }}$, sent into the column has increased at higher initial concentration, thus, increasing the $q_{\text {total }}$. The removal percentage of DCF has decreased with increasing initial concentration. This phenomenon may be attributed to DCF molecules being saturated on the adsorbent active sites when the number of adsorbate molecules far surpassed the available active sites [17].

Table 3. Parameters for breakthrough curves at different initial concentrations.

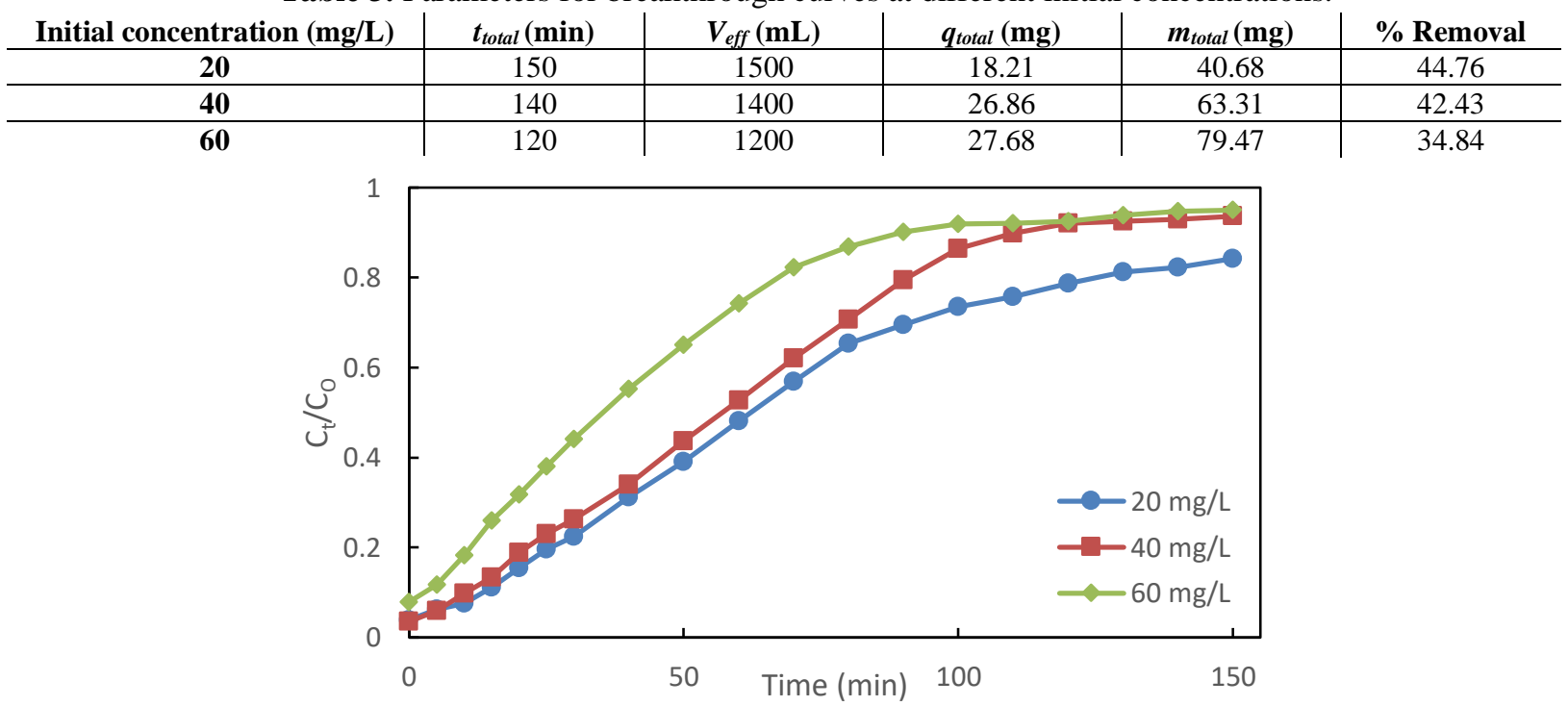

Figure 4. Breakthrough curves at different initial concentrations.

\subsection{Column adsorption model.}

The column adsorption models used to analyze the adsorption behavior of DCF were Bohart and Adams, Yoon-Nelson, and Thomas. The results from the experiments and the breakthrough curves were incorporated into the adsorption models. 


\subsubsection{Bohart and Adams model.}

Bohart and Adams model was applied in this study to assess the adsorption behavior of DCF in a fixed-bed column. In this model, adsorption is believed to occur continuously, and the equilibrium condition for the process will be achieved slowly [29]. The plots and values of each parameter for the Bohart and Adams model are shown in Figure 5 and Table 4. The table shows the value of each parameter at different initial concentrations, bed heights, and flow rates of DCF. As observed from Table 4, when the height of adsorbent in the column is increased from 50 to $100 \mathrm{~mm}$, the values of mass transfer coefficient, $K_{B A}$, and the sorption capacity per unit volume, or the saturation concentration, $N_{o}$, are increased. $K_{B A}$ indicates the amount of DCF adsorbed by a given amount of adsorbent in a given period.

Meanwhile, the adsorbate initial concentration changes have also played a crucial point in determining the adsorption properties. When the initial DCF concentration was increased, the value of $K_{B A}$ started to decrease. This can be assumed to be due to the superior external diffusion at the early phase of DCF adsorption in the column [30]. $K_{B A}$ value was decreased from 0.0012 to $0.0005 \mathrm{~L} / \mathrm{mg} \cdot \mathrm{min}$ when the DCF inlet concentration was increased from 20 to $60 \mathrm{mg} / \mathrm{L}$. A greater concentration gradient will form and reduce the mass transfer coefficient as the concentration rises. A similar trend was seen in an investigation on removing malachite green using calcium alginate, with rising dye concentration leading to a decrease in $K_{B A}$ [13].

The $K_{B A}$ started to decrease when the flow rate was increased, which showed a similar pattern as the effect of initial concentration. This was due to the restricted time for adsorption to occur since the flow of adsorbate through the column was considerably faster at a greater flow of adsorbate per time. Meanwhile, as the initial concentration, flowrate, and bed height of DCF were increased, the value of $N_{o}$ has also increased. The value of $N_{o}$ started to decrease at very high conditions for all parameters. The trends were similar and had no significant differences for all conditions.
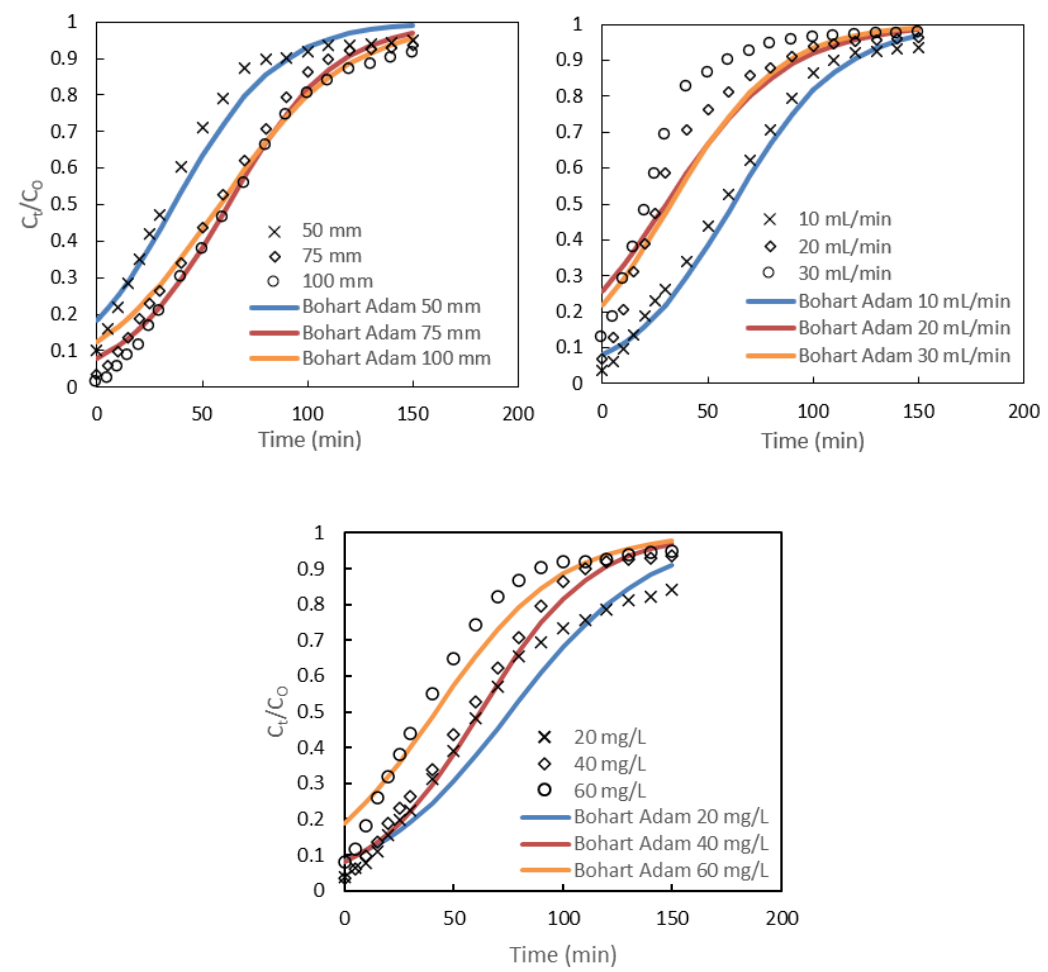

Figure 5. Breakthrough curves of Bohart and Adams model at different parameters: (a) bed height, (b) flow rate, and (c) initial concentration. 
To assess the suitability of this model for the adsorption process, the correlation coefficient, $R^{2}$, and error value, SSE, were employed. As the mathematical nature of all models is comparable, the correlation coefficient value, $R^{2}$, for all models is similar, as shown in Table 4 [23]. All parameters show smaller SSE values, based on the breakthrough curves in Figure 5 for the Thomas model, showing no large differences between them. The breakthrough curves showed good accuracy with the model. This observation suggests that the surface diffusion mechanism was the rate-limiting phase in this adsorption process [14]. A smooth breakthrough curve can be seen for all parameters with high $R^{2}$ and low SSE values. Thus, this model was assumed to be suitable in explaining the adsorption process.

\subsubsection{Yoon-Nelson model.}

The Yoon-Nelson model was also utilized to investigate DCF adsorption. According to this model, the decrease in the rate of adsorption probability of molecules of adsorbates is approximately equal to the probability of adsorbate breakthrough and adsorption $[21,22]$. This model depends only on the adsorption theory and breakthrough data, which shows the simplicity of the model [29]. The time required to reach a breakthrough of $50 \%, \tau$, and the rate constant of Yoon-Nelson, $K_{Y N}$, for all conditions is tabulated in Table 4.

When the adsorbent height was increased from 50 to $100 \mathrm{~mm}$, the values of $\mathrm{K}_{\mathrm{YN}}$ and $\tau$ were also increased from 0.0334 to $0.0407 \mathrm{~min}^{-1}$ and 37.1 to $73.0 \mathrm{~min}$, respectively. These increases are owed to the increase in adsorption sites for DCF. This observation was supported by a study conducted by Sudha et al., which demonstrated that $\tau$ would increase when bed height is increased [31]. The value of $\tau_{\text {exp }}$ for the different bed heights was in line with the $\tau$ value of the Yoon-Nelson model. Although large differences were obtained for these values, the trend for both parameters agreed.

In addition, an increase in $K_{Y N}$ value when the concentration of adsorbate was increased can be presumed to be due to the competitiveness of the adsorbate with the active sites [31]. The $\tau$ value for the Yoon-Nelson model was decreased when the DCF concentration was increased. The reduction of $\tau$ value was because the active sites of the adsorbent were rapidly filled with adsorbate at higher concentrations and less residence time for the adsorption process [31]. At lower concentrations, the adsorbate interaction with the active site would be slower due to less opposition between the molecules. The values of $\tau_{\text {exp }}$ and $\tau$ for this model were not approximate close to each other at different initial concentrations. Nonetheless, the $\tau$ value was decreased with increasing DCF concentration, showing the same trend as the experimental data.

In terms of flow rate, the value of $K_{Y N}$ was decreased when the flow rate was increased between 10 to $30 \mathrm{mg} / \mathrm{L}$. Furthermore, in terms of $\tau$, when the solution flow rate was increased, the period to attain $50 \%$ breakthrough was decreased. The saturation time was reached faster when the solution flow rate was higher, corresponding to the decreasing amount of adsorbate being treated when the flow rate was increased. Kalfa et al. reported the same trend, whereby an increase in the flow rate of adsorbate had caused a reduction in $\tau$ [32].

The lower the value of SSE, the better the adsorption parameter for the breakthrough model. Based on the data in Table 4, the SSE for the Yoon-Nelson model is in the low range as same as other models. Figure 6 demonstrates the Yoon-Nelson plot for three parameters: initial adsorbate concentration, bed height, and flow rate. The depiction of the breakthrough curves agrees well with the experimental findings for all parameters. Yoon-Nelson model is indeed applicable for characterizing the column adsorption's dynamic behavior. 

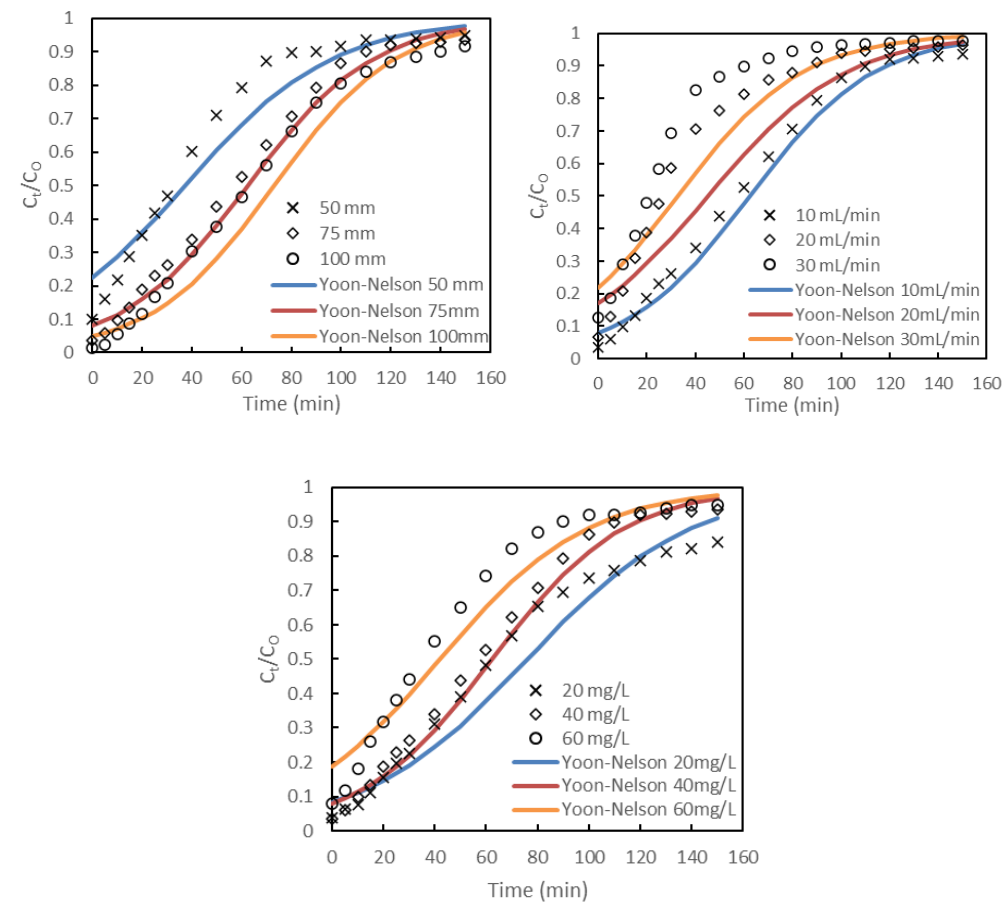

Figure 6. Breakthrough curves of Yoon-Nelson model at different parameters: (a) bed height, (b) flow rate, and (c) initial concentration.

\subsubsection{Thomas model.}

The Thomas model describes the Langmuir isotherm and second-order kinetics. This model was developed based on mass conversion in a flow system [29]. This approach is often utilized to evaluate the adsorption ability of column adsorption. Based on the formula, the value of adsorption capacity, $q_{T H}$, and Thomas rate constant, $K_{T H}$, can feasibly be derived through the intercept and gradient of the linear equation of the Thomas model. The plots and data for each parameter of the Thomas model are illustrated in the following Figure 7 and Table 4. The adsorption capacity, $q_{T H}$, was increased when the initial concentration of DCF was increased, whereas the value of $K_{T H}$ was decreased. This was due to the difference in DCF concentrations and the amount of adsorbent supplying the process of DCF uptakes with a driving force, thus, increasing the value of $q_{T H}$ [33].

In terms of flow rate, when an adsorbate concentration with a specific volume passes through the layer of adsorbent at a given time was increased, the $K_{T H}$ and $q_{T H}$ values were decreased. The experimental adsorption capacity, $q_{\text {exp }}$, and the predicted adsorption capacity, $q_{T H}$, do not agree well at different flow rates of DCF solution. This condition showed that this model was less suitable to describe the effect of flow rate. Meanwhile, when the height of the adsorbent bed rises, the value of $K_{T H}$ will also increase, but the value of $\mathrm{q}_{\mathrm{TH}}$ will decrease. This situation may arise due to the higher mass transfer resistance when the bed height is increased [29]. This can be seen in Figure 7, which shows that the breakthrough curve for a higher bed height is slower than for smaller amounts of adsorbent. In terms of $q_{\exp }$ and $q_{T H}$ at different bed heights, both parameters showed a good relationship, although some differences in value were observed between them. The plot in Figure 7 reveals that the breakthrough curve line and the data point for each parameter are approaching each other, except at a higher flow rate.

This evinces that this model is well-fitted for the adsorption process, with a higher value of $R^{2}$ and a smaller value of SSE. As previously explained, the value of $R^{2}$ for all three models 
was in the same range of 0.88 to 0.97 . Thus, all models were in good agreement with the adsorption process.
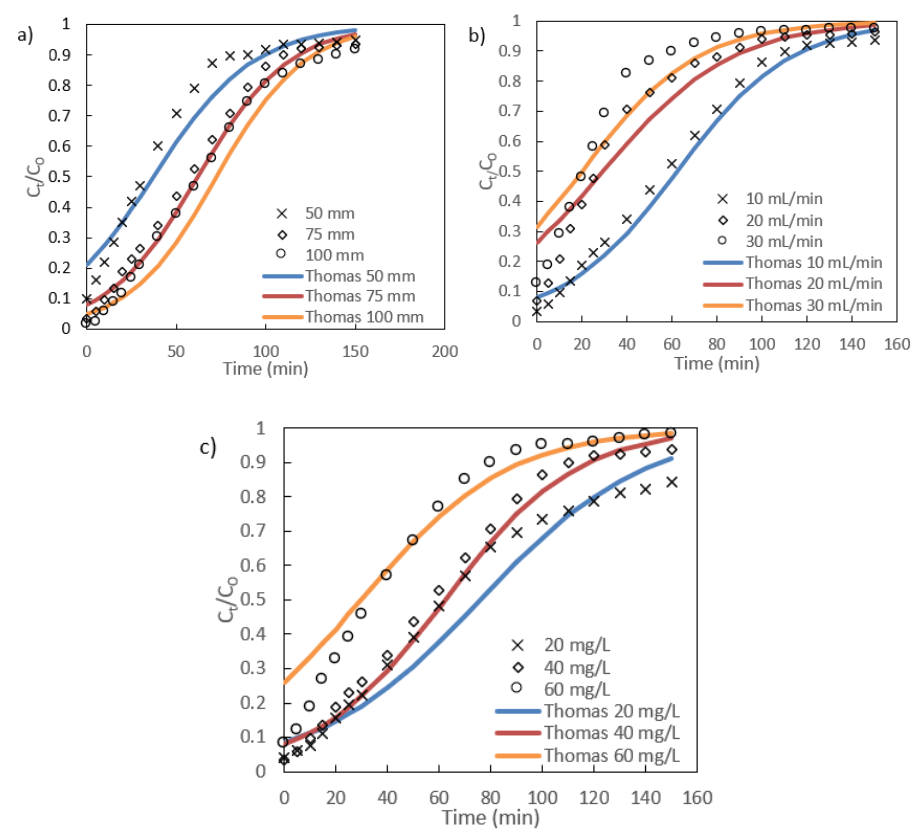

Figure 7. Breakthrough curves of a Thomas model at different parameters: (a) bed height, (b) flowrate, and (c) initial concentration.

Table 4. Parameters and constants of Thomas, Bohart and Adams, and Yoon-Nelson models at different operating conditions.

\begin{tabular}{|c|c|c|c|c|c|c|c|c|c|c|}
\hline \multirow{2}{*}{ Models } & \multirow{2}{*}{ Parameters } & \multicolumn{3}{|c|}{ Flowrate (mL/min) } & \multicolumn{3}{|c|}{ Bed height (mm) } & \multicolumn{3}{|c|}{ Initial concentration $(\mathrm{mg} / \mathrm{L})$} \\
\hline & & 10 & 20 & 30 & 50 & 75 & 100 & 20 & 40 & 60 \\
\hline \multirow[t]{2}{*}{ Experimental } & $q_{\exp }(\mathrm{mg} / \mathrm{g})$ & 5.4 & 3.2 & 2.3 & 6.0 & 5.3 & 4.4 & 3.6 & 5.4 & 5.54 \\
\hline & $T_{\exp }(\min )$ & 57.1 & 26.1 & 20.9 & 32.3 & 57.0 & 63.7 & 62.2 & 57.0 & 35.3 \\
\hline \multirow{4}{*}{$\begin{array}{c}\text { Bohart and } \\
\text { Adams } \\
\text { model }\end{array}$} & $\begin{array}{c}K_{B A} \\
(\mathrm{~L} / \mathrm{mg} \cdot \min )\end{array}$ & 0.0009 & 0.0008 & 0.0008 & 0.0007 & 0.0008 & 0.0009 & 0.0012 & 0.0009 & 0.0005 \\
\hline & $N_{o}(\mathrm{mg} / \mathrm{L})$ & 1473.7 & 1661.3 & 1357.1 & 915.6 & 1473.6 & 1313.5 & 1078.5 & 1473.6 & 1443.1 \\
\hline & $\mathbf{R}^{2}$ & 0.963 & 0.899 & 0.882 & 0.918 & 0.963 & 0.940 & 0.935 & 0.963 & 0.925 \\
\hline & SSE & 0.038 & 9.805 & 0.026 & 5.757 & 0.065 & 0.156 & 0.077 & 0.065 & 0.028 \\
\hline \multirow{4}{*}{$\begin{array}{c}\text { Yoon-Nelson } \\
\text { model }\end{array}$} & $K_{Y N}\left(\min ^{-1}\right)$ & 0.0390 & 0.0360 & 0.0360 & 0.0334 & 0.0392 & 0.0407 & 0.0003 & 0.0392 & 0.0351 \\
\hline & $\tau(\min )$ & 62.4 & 34.8 & 19.9 & 37.1 & 62.4 & 73.0 & 76.0 & 62.4 & 43.0 \\
\hline & $R^{2}$ & 0.963 & 0.899 & 0.882 & 0.918 & 0.963 & 0.940 & 0.934 & 0.963 & 0.925 \\
\hline & SSE & 0.060 & 9.739 & 8.162 & 0.356 & 0.076 & 0.134 & 0.081 & 0.075 & 0.132 \\
\hline \multirow{4}{*}{$\begin{array}{c}\text { Thomas } \\
\text { model }\end{array}$} & $\begin{array}{c}K_{T H} \\
(\mathrm{~L} / \mathrm{mg} \cdot \min )\end{array}$ & 0.0009 & 0.0008 & 0.0008 & 0.0007 & 0.0008 & 0.0009 & 0.0010 & 0.0008 & 0.0005 \\
\hline & $q_{T H}(\mathrm{mg} / \mathrm{g})$ & 5.6 & 5.3 & 5.2 & 5.4 & 5.3 & 4.7 & 4.1 & 5.6 & 5.7 \\
\hline & $R^{2}$ & 0.963 & 0.899 & 0.882 & 0.918 & 0.963 & 0.940 & 0.935 & 0.963 & 0.925 \\
\hline & SSE & 0.040 & 4.368 & 8.334 & 0.409 & 0.005 & 0.102 & 0.211 & 0.065 & 0.026 \\
\hline
\end{tabular}

\section{Conclusions}

This study has successfully eliminated DCF from an aqueous solution using Dillenia Indica peels as activated carbon. The activated carbon was produced using the phosphoric acid activation method. Based on the findings, it was inferred that DCF adsorption was governed by its initial concentration, adsorbent bed height, and adsorbate flow rate. Adsorption was favorable at low flow rates, with the removal percentage of DCF decreasing with increasing flow rate. Additionally, an increase in the initial concentration of DCF and the adsorbent bed height has increased the DCF removal percentage. The breakthrough curves were also steeper at higher initial concentrations. At $10 \mathrm{~mL} / \mathrm{min}$ of flow rate, $40 \mathrm{mg} / \mathrm{L}$ of adsorbate concentration, and $100 \mathrm{~mm}$ of bed height, the highest quantity of DCF adsorbed, $30.63 \mathrm{mg}$, was achieved, 
with a removal percentage $44.93 \%$. The breakthrough data were examined by utilizing the Bohart and Adams, Yoon-Nelson, and Thomas models. Based on the results, these models were suitable for explaining the column's dynamic behavior for the adsorption process. This conclusion was drawn from the difference between a predicted and experimental parameter designated as SSE. Thus, Dillenia Indica peels, as activated carbon, may be utilized as an acceptable adsorbent in a fixed-bed adsorption column for removing DCF. Its efficacy in the laboratory showed that it could be applied in a real-world application.

\section{Funding}

This research was funded by the Ministry of Education (MOE) under the Fundamental Research Grant Scheme (FRGS), grant number: FRGS /1/ 2019/ 9003-00712.

\section{Acknowledgments}

The authors would like to acknowledge the Faculty of Civil Engineering Technology of Universiti Malaysia Perlis for providing research facilities and technical support for this study.

\section{Conflicts of Interest}

The authors declare no conflict of interest.

\section{References}

1. Gan, T.J. Diclofenac: An update on its mechanism of action and safety profile. Curr Med Res Opin 2010, 26, 1715-1731, https://doi.org/10.1185/03007995.2010.486301.

2. Kun, Z.; Yanjie, L. Research progress of synthesis of diclofenac sodium, Topics in Chemical \& Material Engineering. New Mater Intell Manuf 2018, 1, 276-279, https://doi.org/10.26480/icnmim.01.2018.276.279.

3. Hartmann, A.; Erkman, L.; Maremanda, N.; Elhajouji, A.; Martus, H.J. Comprehensive review of genotoxicity data for diclofenac. Mutat Res - Genet Toxicol Environ Mutagen 2021, 866, https://doi.org/10.1016/j.mrgentox.2021.503347.

4. van-Walsem, A.; Pandhi, S.; Nixon, R.M.; Guyot, P.; Karabis, A.; Moore, R.A. Relative benefit-risk comparing diclofenac to other traditional non-steroidal anti-inflammatory drugs and cyclooxygenase-2 inhibitors in patients with osteoarthritis or rheumatoid arthritis: A network meta-analysis. Arthritis Res Ther 2015, 17.

5. Tyumina, E.A.; Bazhutin, G.A.; Cartagena, Gómez, A.D.P.; Ivshina, I.B. Nonsteroidal anti-inflammatory drugs as emerging contaminants. Microbiol 2020, 89, 148-163, https://doi.org/10.1134/s0026261720020125.

6. Ali, A.M.M.; Kallenborn, R.; Sydnes, L.K.; Rønning, H.T.; Alarif, W.M.; Al-Lihaibi, S. Photolysis of pharmaceuticals and personal care products in the marine environment under simulated sunlight conditions: irradiation and identification. Environ Sci Pollut Res 2017, 24, 14657-14668, https://doi.org/10.1007/s11356017-8930-8.

7. Mezzelani, M.; Gorbi, S.; Fattorini, D.; d'Errico, G.; Consolandi, G.; Milan, M.; Bargelloni, L.; Regoli, F. Long-term exposure of Mytilus galloprovincialis to diclofenac, Ibuprofen and Ketoprofen: Insights into bioavailability, biomarkers and transcriptomic changes. Chemosphere 2018, 198, 238-248, https://doi.org/10.1016/j.chemosphere.2018.01.148.

8. Huang, Z.; Gong, B.; Huang, C.-P.; Pan, S.-Y.; Wu, P.; Dang, Z.; Chiang, P.-C. Performance evaluation of integrated adsorption-nanofiltration system for emerging compounds removal: Exemplified by caffeine, diclofenac and octylphenol. $J$ Environ Manage 2019, 231, 121-128, https://doi.org/10.1016/j.jenvman.2018.09.092.

9. Park, J.; Yamashita, N.; Tanaka, H. Membrane fouling control and enhanced removal of pharmaceuticals and personal care products by coagulation-MBR. Chemosphere 2018, 197, 467-476, https://doi.org/10.1016/j.chemosphere.2018.01.063.

10. Kharel, S.; Stapf, M.; Miehe, U.; Ekblad, M.; Cimbritz, M.; Falås, P.; Nilsson, J.; Sehlén, R.; Bregendahl, J.; Bester, K. Removal of pharmaceutical metabolites in wastewater ozonation including their fate in different post-treatments. Sci Total Environ 2021, 759, https://doi.org/10.1016/j.scitotenv.2020.143989.

11. Kuang, Y.; Zhang, X.; Zhou, S. Adsorption of methylene blue in water onto activated carbon by surfactant modification. Water 2020, 12, https://doi.org/10.3390/w12020587.

12. Mirzaee, S.A.; Bayati, B.; Valizadeh, M.R.; Gomes, H.T.; Noorimotlagh, Z. Adsorption of diclofenac on 
mesoporous activated carbons: Physical and chemical activation, modeling with genetic programming and molecular dynamic simulation. Chem Eng Res Des 2021, 167, 116-128, https://doi.org/10.1016/j.cherd.2020.12.025.

13. Nath, J.; Ray, L.; Bera, D. Continuous removal of malachite green by calcium alginate immobilized Bacillus cereus M116 in packed bed column. Environ Technol Innov 2016, 6, 132-140, https://doi.org/10.1016/j.eti.2016.06.002.

14. de-Franco, M.A.E.; de-Carvalho, C.B.; Bonetto, M.M.; Soares, R.P.; Feris, L.A. Removal of amoxicillin from water by adsorption onto activated carbon in batch process and fi xed bed column: Kinetics, isotherms, experimental design and breakthrough curves modelling. J Clean Prod 2017, 161, 947-956, https://doi.org/10.1016/j.jclepro.2017.05.197.

15. Shirani, Z.; Song, H.; Bhatnagar, A. Efficient removal of diclofenac and cephalexin from aqueous solution using Anthriscus sylvestris-derived activated biochar. Sci Total Environ 2020, 745, https://doi.org/10.1016/j.scitotenv.2020.140789.

16. Elabadsa, M.; Varga, M.; Mihucz, V.G. Removal of selected pharmaceuticals from aqueous matrices with activated carbon under flow conditions. Microchem J 2019, 150, https://doi.org/10.1016/j.microc.2019.104079.

17. Yahya, M.D.; Aliyu, A.S.; Obayomi, K.S.; Olugbenga, A.G.; Abdullahi, U.B. Column adsorption study for the removal of chromium and manganese ions from electroplating wastewater using cashew nutshell adsorbent. Cogent Eng 2020, 7, https://doi.org/10.1080/23311916.2020.1748470.

18. Han, R.; Zou, W.; Li, H.; Li, Y.; Shi, J. Copper (II) and lead (II) removal from aqueous solution in fixed-bed columns by manganese oxide coated zeolite. J Hazard Mater 2006, 137, 934-942, https://doi.org/10.1016/j.jhazmat.2006.03.016.

19. Charola, S.; Yadav, R.; Das, P.; Maiti, S. Fixed-bed adsorption of Reactive Orange 84 dye onto activated carbon prepared from empty cotton flower agro-waste. Sustain Environ Res 2018, 28, 298-308, https://doi.org/10.1016/j.serj.2018.09.003.

20. Alardhi, S.M.; Albayati, T.M.; Alrubaye, J.M. Adsorption of the methyl green dye pollutant from aqueous solution using mesoporous materials MCM-41 in a fixed-bed column. Heliyon 2020, 6, https://doi.org/10.1016/j.heliyon.2020.e03253.

21. Vera, M.; Juela, D.M.; Cruzat, C.; Vanegas, E. Modeling and computational fluid dynamic simulation of acetaminophen adsorption using sugarcane bagasse. $J$ Environ Chem Eng 2021, 9, https://doi.org/10.1016/j.jece.2021.105056.

22. Yoon, Y.H.; Nelson, J.H. Application of Gas Adsorption Kinetics I. A Theoretical Model for Respirator Cartridge Service Life. Am Ind Hyg Assoc J 1984, 45, 509-516, https://doi.org/10.1080/15298668491400197.

23. Bakka, A.; Mamouni, R.; Saffaj, N.; Laknifli, A.; Aziz, K.; Roudani A. Removal of bifenthrin pesticide from aqueous solutions by treated patellidae shells using a new fixed bed column filtration technique. Process Saf Environ Prot 2020, 143, 55-65, https://doi.org/10.1016/j.psep.2020.06.030.

24. Iheanacho, O.C.; Nwabanne, J.T.; Obi, C.C.; Onu, C.E. Packed bed column adsorption of phenol onto corn cob activated carbon: linear and nonlinear kinetics modeling. South African J Chem Eng 2021, 36, 80-93, https://doi.org/10.1016/j.sajce.2021.02.003.

25. Fallah, N.; Taghizadeh, M. Continuous fixed-bed adsorption of Mo(VI) from aqueous solutions by Mo (VI)IIP: Breakthrough curves analysis and mathematical modeling. J Environ Chem Eng 2020, 8, https://doi.org/10.1016/j.jece.2020.104079.

26. Topare, N.S.; Bokil, S.A. Adsorption of textile industry effluent in a fixed bed column using activated carbon prepared from agro-waste materials. Mater Today Proc 2020, 43, 530-534, https://doi.org/10.1016/j.matpr.2020.12.029.

27. González-López, M.E.; Pérez-Fonseca, A.A.; Arellano, M.; Gómez, C.; Robledo-Ortíz, J.R. Fixed-bed adsorption of $\mathrm{Cr}(\mathrm{VI})$ onto chitosan supported on highly porous composites. Environ Technol Innov 2020, 19, https://doi.org/10.1016/j.eti.2020.100824.

28. Lakshmipathy, R.; Sarada, N.C. A fixed bed column study for the removal of $\mathrm{Pb} 2+$ ions by watermelon rind. Environ Sci Water Res Technol 2015, 1, 244-250, https://doi.org/10.1039/c4ew00027g.

29. Satya, A.; Harimawan, A.; Sri Haryani, G.; Johir, M.A.H.; Nguyen, L.N.; Nghiem, L.D.; Vigneswaran, S.; Ngo, H.H.; Setiadi, T. Fixed-bed adsorption performance and empirical modelingof cadmium removal using adsorbent prepared from the cyanobacterium Aphanothece sp cultivar. Environ Technol Innov 2021, 21, https://doi.org/10.1016/j.eti.2020.101194.

30. Ostaszewski, P.; Długosz, O.; Banach, M. Analysis of measuring methods of the concentration of methylene blue in the sorption process in fixed-bed column. Int $J$ Environ Sci Technol 2021, https://doi.org/10.1007/s13762-021-03156-X.

31. Vijayalakshmi, K.; Sudha, P.N. Modeling Fixed Bed Column for Lead (II) Removal From Aqueous Solution Using Nanochitosan/Sodium Alginate/Microcrystalline Cellulose Beads. World J Pharm Res 2018, 7, 340362.

32. Khalfa, L.; Sdiri, A.; Bagane, M.; Cervera, M.L. A calcined clay fixed bed adsorption studies for the removal of heavy metals from aqueous solutions. J Clean Prod 2021, 278, https://doi.org/10.1016/j.jclepro.2020.123935. 
33. Mahmoud, M.A. Kinetics studies of uranium sorption by powdered corn cob in batch and fixed bed system. $J$ Adv Res 2016, 7, 79-87, https://doi.org/10.1016/j.jare.2015.02.004. 